
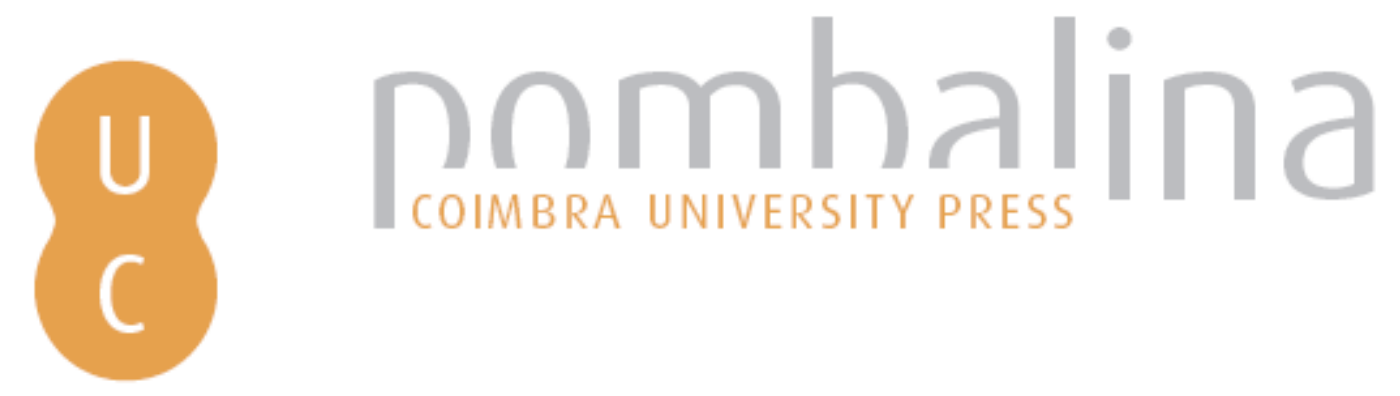

\title{
Plano diretor da refuncionalização da Fortaleza
}

Autor(es): $\quad$ Aguacheiro, Jaime; Lopes, Nuno

Publicado por: Imprensa da Universidade de Coimbra

URL

persistente: URI:http://hdl.handle.net/10316.2/44313

DOI: $\quad$ DOl:https://doi.org/10.14195/978-989-26-1556-1_8

Accessed : $\quad$ 26-Apr-2023 13:54:13

A navegação consulta e descarregamento dos títulos inseridos nas Bibliotecas Digitais UC Digitalis, UC Pombalina e UC Impactum, pressupõem a aceitação plena e sem reservas dos Termos e Condições de Uso destas Bibliotecas Digitais, disponíveis em https://digitalis.uc.pt/pt-pt/termos.

Conforme exposto nos referidos Termos e Condições de Uso, o descarregamento de títulos de acesso restrito requer uma licença válida de autorização devendo o utilizador aceder ao(s) documento(s) a partir de um endereço de IP da instituição detentora da supramencionada licença.

Ao utilizador é apenas permitido o descarregamento para uso pessoal, pelo que o emprego do(s) título(s) descarregado(s) para outro fim, designadamente comercial, carece de autorização do respetivo autor ou editor da obra.

Na medida em que todas as obras da UC Digitalis se encontram protegidas pelo Código do Direito de Autor e Direitos Conexos e demais legislação aplicável, toda a cópia, parcial ou total, deste documento, nos casos em que é legalmente admitida, deverá conter ou fazer-se acompanhar por este aviso.

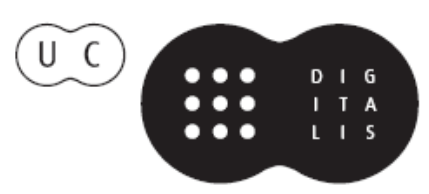




\section{OFICINAS DE \\ MUHIPITI \\ planeamento estratégico \\ património \\ desenvolvimento}

organização:

Walter Rossa

Nuno Lopes

Nuno Simão Gonçalves

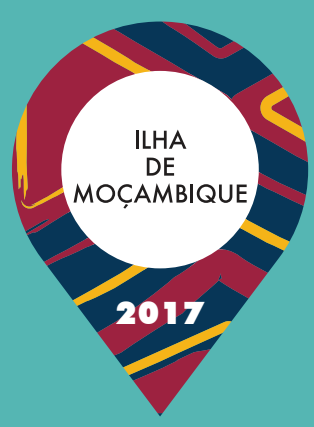




\title{
PLANO DIRETOR DA REFUNCIONALIZAÇÃO DA FORTALEZA
}

\author{
Jaime Aguacheiro \\ Nuno Lopes
}

\author{
Missão-encomenda previamente formulada
}

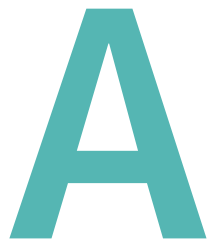

Fortaleza de São Sebastião da llha de Moçambique foi entregue à Universidade Lúrio para instalação da sua Faculdade de Ciências Sociais e Humanas, o que constituiu o ponto de partida para a produção deste evento. A fortaleza é, provavelmente, o conjunto edificado com maior simbolismo da llha e tem sido objeto de diversas ações de restauro elou reabilitação que, perante a falta de função, rapidamente entram em processo de degradação. A instalação da faculdade pode ser a solução ou mais um problema, tudo dependendo do conceito que vier a ser adotado na sua refuncionalização. Na conceção deste evento partiu-se do pressuposto de que o conceito da instalação daquela faculdade na fortaleza deverá contemplar o fomento da instalação e desenvolvimento de um conjunto de empresas locais, que assim se especializem em trabalhos realizados em contexto patrimonial de grande relevância e possam desenvolver a sua atividade não só na construção e manutenção deste conjunto, mas no muito que há para fazer em toda a Ilha. Para tal é crucial que o Plano Diretor que venha a ser adotado privilegie intervenções faseadas e de pequena e/ou média dimensão, e dê indicações muito concretas sobretudo de forma a que o resultado das diversas intervenções, muito provavelmente desfasadas no tempo, resulte harmonioso. Importa ter presente, recolher a informação e dinamizar a interação requeridas pelo facto de estar previsto que outros organismos, que não apenas a universidade, também se instalem na fortaleza e, claro, que se trata de um conjunto com grande atratividade para turistas e locais. 
A fortaleza tem sido objeto de diversas ações de restauro/ reabilitação (Eloudou e Weydt, 2009) que, perante a falta de função, entra rápida e repetidamente num processo de degradação, conforme registado pelo arquiteto José Forjaz no relatório Island of Mozambique: Architectural survey and study on local vernacular architecture (2010, 94-95). Com efeito, apesar das diversas intervenções realizadas há alguns anos (com destaque para o conjunto de ações dirigidas pela fundação japonesa) (Berti, 2014), estas parecem insustentáveis.

Em 2016, a pedido do Reitor da Universidade Lúrio, a FAPF, sob coordenação do arquiteto Maurizio Berti, elaborou um projeto de reutilização cujo elevado custo de obra o tornou inviável. Segundo o relatório Considerações preliminares às obras de restauro e de adaptação necessárias para acomodar a Faculdade de Ciências Sociais e Humanas nos espaços da Fortaleza de São Sebastião na Ilha de Moçambique, essa intervenção de reabilitação (uma área de $4.850 \mathrm{~m}^{2}$ ), teria um custo de USD\$7.275.000. As propostas de ocupação incluem o estabelecimento no complexo da fortaleza da referida faculdade e de outras instituições, assim como a reversão de alguns erros de conservação aí perpetrados.
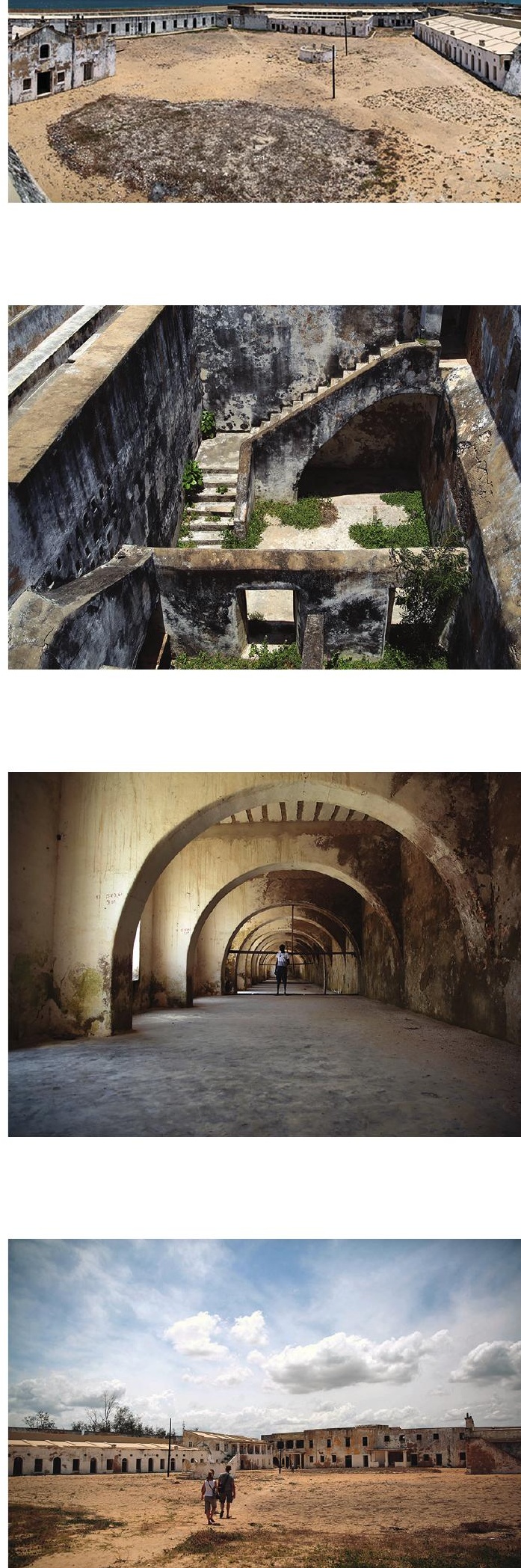


\section{ANÁLISE}

Foi com base nestes dados, na extensa quantidade de estudos sobre a Ilha e a fortaleza, e sensível às situações social, política e económica da Ilha e do país, que a oficina abraçou este desafio. Temos consciência de que a instalação deste polo universitário poderá vir a ser a solução para muitos dos problemas, ou um novo problema a juntar aos restantes, dependendo do conceito e método de implementação que vierem a ser adotados na sua refuncionalização.

A missão destinada a esta oficina consistiu numa espécie de encomenda: tomar como ponto de partida os projetos anteriores e cumprir os desígnios de salvaguarda patrimonial, propor soluções exemplificativas para uma execução de baixo custo e especialização, permitindo promover a contratação de pequenos empreiteiros da região. Nesse sentido, o conceito da instalação da faculdade deverá contemplar o fomento da instalação de um conjunto de empresas locais, que assim se especializem em trabalhos realizados em contexto patrimonial de grande relevância e permitam o desenvolvimento da sua atividade profissional, tanto na construção e manutenção deste conjunto, como no muito que há para fazer em todo o município.

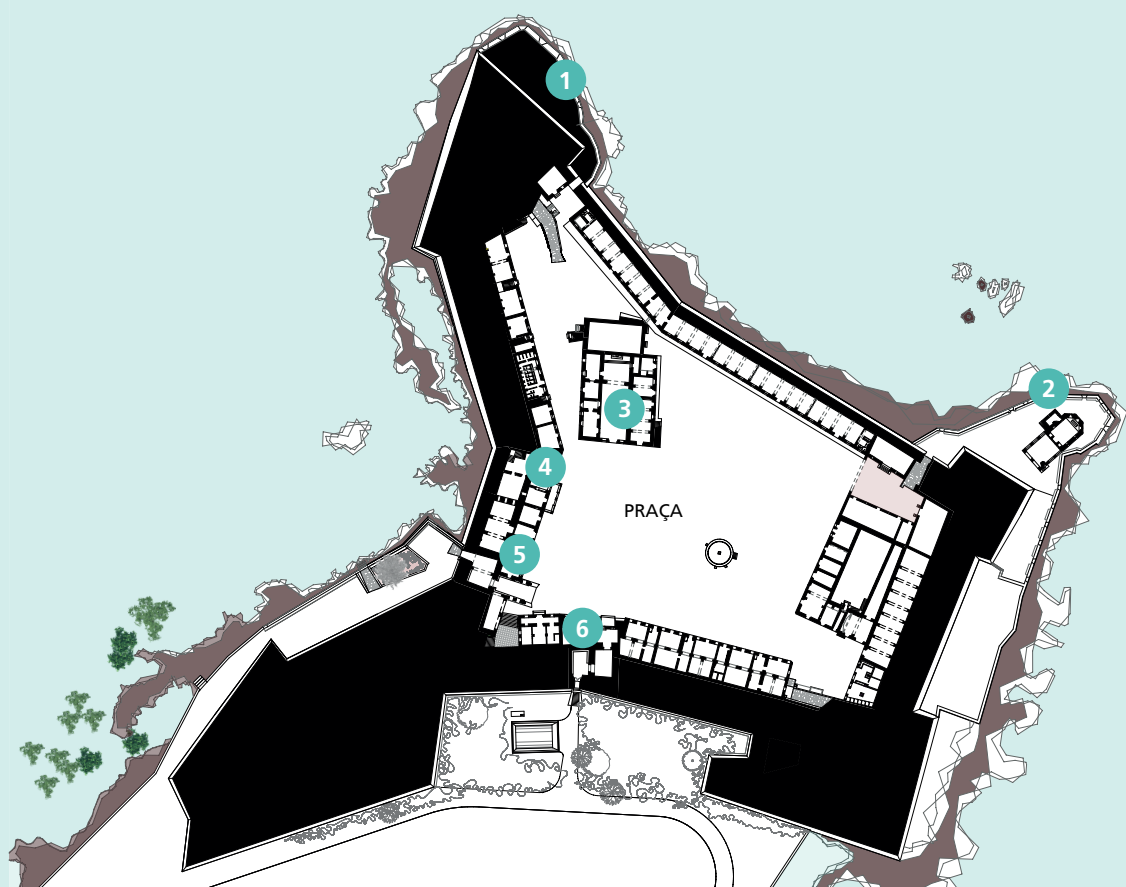


Na análise que a oficina fez às intervenções e propostas anteriores rapidamente percebeu que, embora nem tudo tenha corrido mal, os custos de intervenção, conservação e manutenção são demasiado elevados face aos recursos disponíveis. Verificou-se, com agrado, que as poucas estruturas em atividade - e, portanto, com uma mínima manutenção diária - mantiveram razoável estado geral de conservação. As instalações abandonadas, na grande maioria, apresentam, entre outros, problemas de erosão, instabilidade estrutural, infiltrações, humidade descontrolada (sobretudo em elementos adjacentes aos baluartes) e escassez de ventilação.

\section{LE GENDA}

(1) Erosão da base coralífera

(2) Destruição do muro pelo ciclone (2008)

(3) Lixiviação das águas pluviais

(4) Instabilidade estrutural

5. Infiltrações nos tetos e janelas

6 Humidade das paredes adjacentes aos baluartes
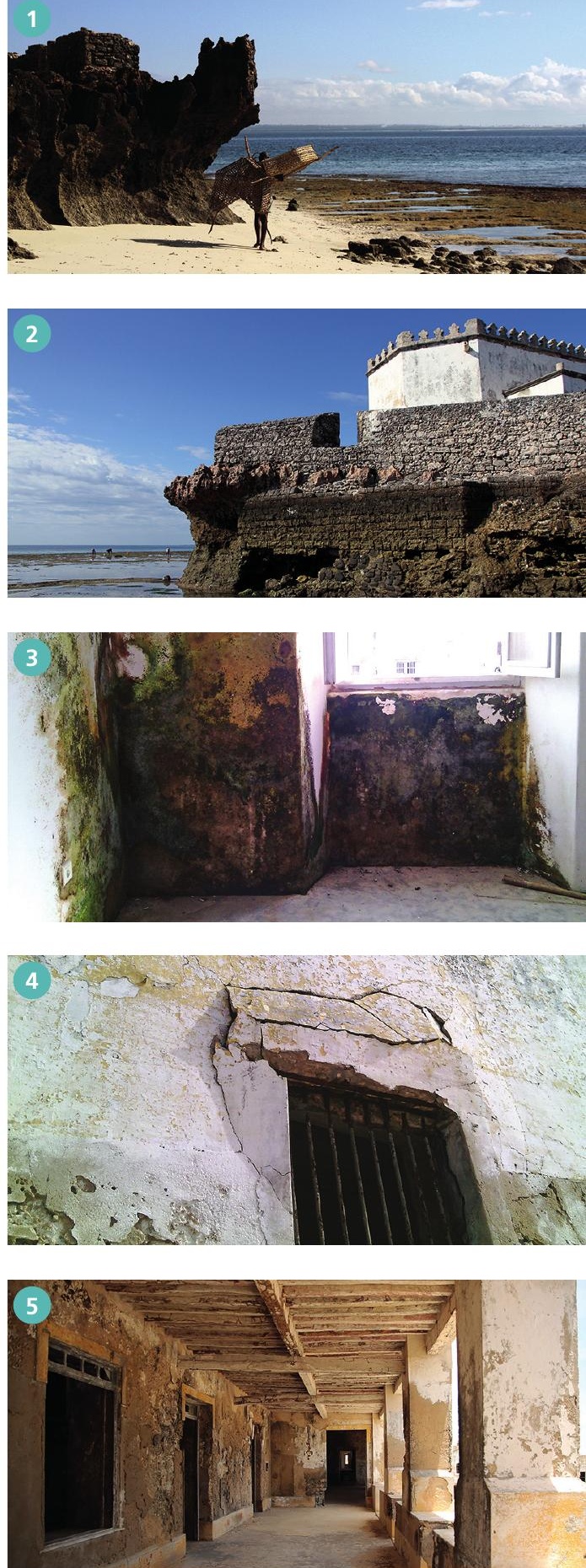

6

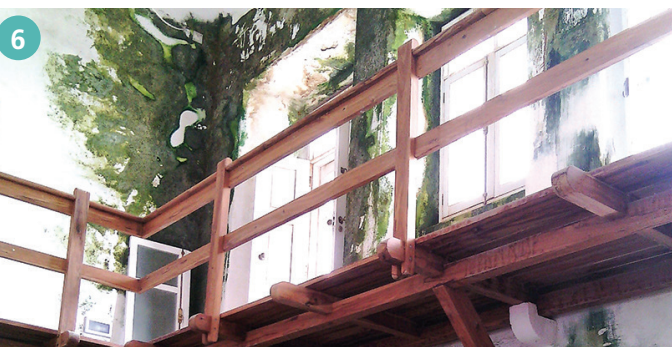




\section{PROPOSTA}

Apresentado e analisado o desafio, poderemos desde logo tirar duas conclusões:

- Que este conjunto de pressupostos permite à Universidade Lúrio gerir o processo inicial de refuncionalização da fortaleza, garantindo um controlo sobre a definição de intervenções futuras, faseadas segundo as suas prioridades institucionais, ao mesmo tempo que promove o desenvolvimento sustentável da construção, economia e emprego locais. Para tal, será crucial que o plano diretor a adotar apresente indicações muito concretas, garantindo um resultado final harmonioso;

- Que, numa segunda fase e para além da universidade, está previsto que outros organismos se instalem neste complexo, conjunto edificado de importância singular na identidade da llha, com grande atratividade para turistas e locais.

A proposta desta oficina concentrou-se, pois, numa tentativa de dar resposta aos diversos pedidos e expectativas de salvaguarda patrimonial, propondo soluções exemplares para uma execução de baixo custo e especialização, sob um ritmo faseado. Nesse sentido, identificados os principais problemas de conservação do edifício e algumas das prioridades de ocupação, foi desenvolvida uma proposta preliminar para um plano diretor de refuncionalização sob gestão direta da UniLúrio.

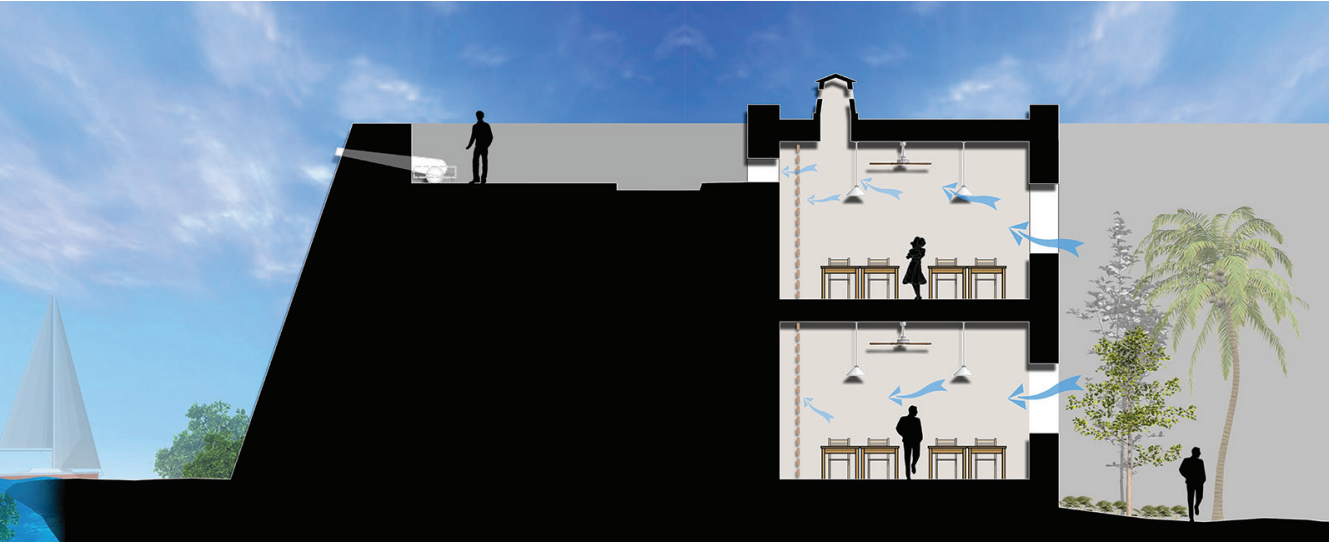




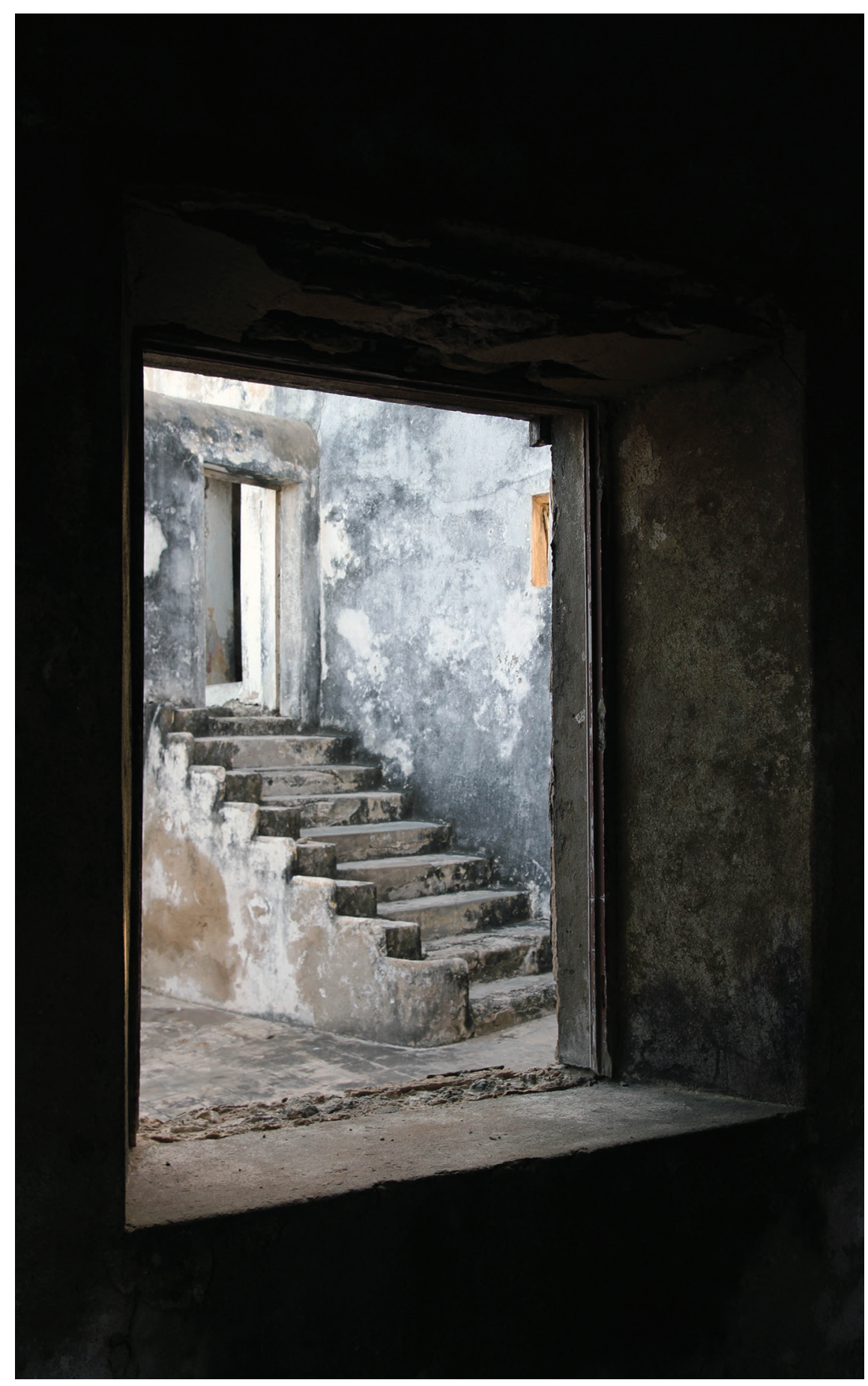






Está prevista uma ocupação inaugural no conjunto edificado da frente oeste. Foram consideradas as estruturas atuais, a necessitar da implementação imediata de trabalhos de acabamentos - pisos, paredes, tetos, portas, janelas, etc. - e de sistemas - água e eletricidade, com respetivos abastecimento, saneamento e drenagem, ligações às redes disponíveis e estudo de alternativas.

Nessa primeira fase de intervenção é proposta a organização do rés do chão de forma a receber pelo menos 10 salas (consoante as necessidades e respetiva adaptação das mesmas) das quais 6 seriam de aulas (com capacidade para acolher até 150 alunos) e as restantes destinadas à direção e apoio, atendimento ao turista e sanitários (já existentes, a precisar de uma reabilitação). No primeiro andar assumindo que poderia corresponder já a uma segunda fase de obras e em simultâneo com o decurso de aulas ao nível térreo - propõe-se a instalação de 10 novas salas de aula, de maior dimensão (com capacidade para acolher até 400 alunos), sala de estudo, reprografia e espaço expositivo (também importante para a distribuição de espaços e circulação dos utentes). Esta ampliação contemplaria a possibilidade de integração de novos cursos. 
No flanco oposto, a leste, encontra-se a principal cisterna da fortaleza. O conjunto de edifícios que a envolve foi escolhido para receber a cantina e respetivas áreas de apoio.

Para além destas duas frentes, está prevista a ocupação da antiga igreja, sendo proposta a sua reconfiguração como auditório, uma espécie de aula-magna, podendo vir a ser usado por outras instituições que se venham a instalar no complexo. As naves laterais serão facilmente convertíveis em áreas de apoio, incluindo a cisterna aí existente.

À frente dessa igreja está o flanco sul da fortaleza, outrora a entrada principal, ultrapassado o fosso que a separava de terra firme. É proposta a sua reabertura (sendo desmontada a cisterna mais recente e já desativada, ali existente) assim como a instalação do CEDIM e uma biblioteca-arquivo da FCSH, que poderiam vir a formar um organismo único. 


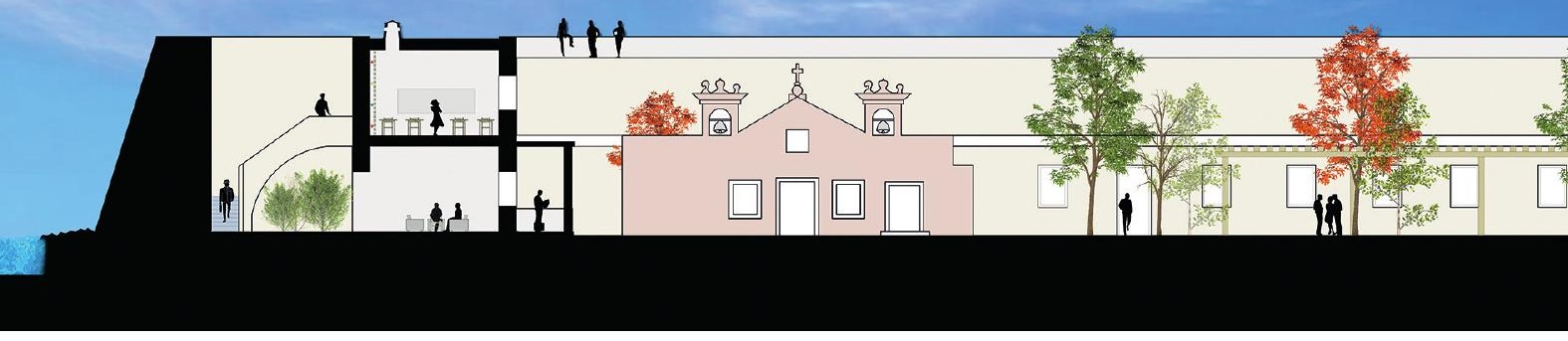

Como resposta aos principais problemas que afetam a conservação das diversas estruturas existentes, foram privilegiadas opções reversíveis, de baixo custo e fácil implementação. Delas são exemplo:

- A fixação de painéis à base de paletes de madeira, suportados por estruturas simples, também de madeira, à parede de alvenaria existente. Esta opção permite a simplificação de montagem/ desmontagem e gestão regular dos sistemas de água, energia e comunicações;

- Potencializar a circulação de ar no interior, reduzindo a temperatura e a concentração de humidade, sobretudo ao nível sensorial, melhorando a sua habitabilidade.

As propostas consideraram a articulação da faculdade com outros organismos, nomeadamente o CEDIM, o GACIM e o potencial Museu Marítimo, revelando- se fundamental a harmonia e bem-estar do e no conjunto. Para isso será ainda decisiva a intervenção de arranjo dos espaços exteriores, designadamente a criação de áreas verdes, percursos e zonas de estar, resultando numa proposta de reconfiguração global do pátio central. O recurso a elementos de construção ligeira (p. e., pérgulas em madeira) privilegiariam dois aspetos:

- A criação de percursos e zonas de estar, podendo ser utilizadas para aula ao ar livre, como esplanada junto à cantina, zonas de lazer, etc.

- A reconfiguração e redimensionamento do pátio central, abrindo-se sobre os flancos (que correspondem aos principais acessos da fortaleza), resguardando-se nos restantes e tornado o espaço exterior mais habitável. 


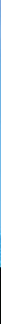

A colocação de vegetação em zonas estratégicas procura contribuir para esta reconfiguração da praça, privilegiando um maior conforto num clima particularmente difícil. A organização das circulações a dois níveis - pátio e caminhos de ronda - é também importante, tanto para os utilizadores assíduos desses espaços, como para os turistas ou habitantes da llha que pretendam fruir da fortaleza.

No curto espaço de tempo em que a oficina se pôde dedicar a este desafio, uma ideia ficou absolutamente clara: a Fortaleza de São Sebastião é o grande símbolo do património edificado da llha e deverá estar de portas abertas à comunidade. Esta proposta pretende contribuir para que tal aconteça.

LEGE N A

ÁREAS VERDES

SALAS DE AULAS - FCSH

DIREÇÃO E APOIO - FCSH

AUDITÓRIO

CEDIM

MUSEU MARITIMO

APOIO AO TURISTTA

PÉRGOLA

CISTERNA

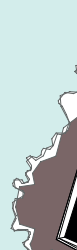

入 


\section{REFERÊNCIAS BIBLIOGRÁFICAS}

BERTI, Maurizio (2014), Conservation of the Fortress of São Sebastião, Ilha de Mozambique. Consultado a 01.05.2017, em: https://www.wmf.org/ blog/conservation-fortress-s\%C3\%A3o-sebasti\%C3\%A3o-ilha-demozambique.

BERTI, Maurizio (2016), Considerações preliminares às obras de restauro e de adaptação necessárias para acomodar a Faculdade de Ciências Sociais e Humanas nos espaços da Fortaleza de São Sebastião na Ilha de Moçambique. Nampula: relatório encomendado pelo Magnifico Reitor da Universidade Lúrio.

ELOUNDOU, Lazare; WEYDT, Jana (2009), Rehabilitation of the Saint Sebastian Fortress, Island of Mozambique. Paris: UNESCO.

FORJAZ, José (2010), Island of Mozambique - Architectural survey and study on local vernacular architecture. Maputo.

GONÇALVES, Nuno Simão (2011), O projecto para a fortaleza da llha de Moçambique atribuído a Miguel de Arruda. Coimbra: Dissertação de Mestrado em Arquitetura, apresentado à Faculdade de Ciências e Tecnologia da Universidade de Coimbra. 